\title{
CCM2 gene polymorphisms in Italian sporadic patients with cerebral cavernous malformation: A case-control study
}

\author{
ROSALIA D'ANGELO ${ }^{1}$, CONCETTA SCIMONE ${ }^{1}$, CARMELA RINALDI $^{1}$, GIUSEPPE TRIMARCHI ${ }^{2}$, \\ DOMENICO ITALIANO ${ }^{3}$, PLACIDO BRAMANTI ${ }^{3}$, ALDO AMATO ${ }^{1}$ and ANTONINA SIDOTI ${ }^{1}$ \\ ${ }^{1}$ Department of Biomorphology and Biotechnologies, Division of Biology and Genetics, University of Messina, \\ I-98125 Messina; ${ }^{2}$ Department of Economical, Financial, Social, Environmental, Statistical and \\ Territorial Sciences, University of Messina, viale Italia; ${ }^{3}$ IRCCS Centro Neurolesi \\ 'Bonino-Pulejo', Contrada Casazza, I-98122 Messina, Italy
}

Received September 29, 2011; Accepted November 24, 2011

DOI: 10.3892/ijmm.2012.927

\begin{abstract}
Cerebral cavernous malformations (CCMs) are vascular lesions of the CNS characterized by abnormally enlarged capillary cavities that can occur sporadically or as a familial autosomal dominant condition with incomplete penetrance and variable clinical expression attributable to mutations in three different genes: CCM1 (Krit1), CCM2 (MGC4607) and CCM3 (PDCD10). Among our group of CCM Italian patients, we selected a cohort of sporadic cases negative for mutations in CCM genes. In this cohort, five variants in CCM2 gene were detected, which proved to be the known polymorphisms in intronic regions (IVS2-36A $>\mathrm{G}$ and IVS8 $+119 \mathrm{C}>\mathrm{T}$ ) and in coding sequence (c.157 $\mathrm{G}>\mathrm{A}$ in exon 2 , c. $358 \mathrm{G}>\mathrm{A}$ in exon 4 and c.915 G>A in exon 8). Therefore, we undertook a casecontrol study to investigate the possible association of these polymorphisms with sporadic CCMs. The five polymorphisms were identified in 91 CCM sporadic patients and in 100 healthy controls by direct sequencing methods using lymphocyte DNA. Polymorphisms IVS2-36A $>$ G and c.915 G >A showed statistically significant differences in frequencies between patients and controls $\left[\left(\chi^{2}, 6.583 ; \mathrm{P}<0.037\right) ;\left(\chi^{2}, 14.205 ; \mathrm{P}<0.001\right)\right]$. The prevalence of the wild-type genotype was significantly lower in the CCM group than in the control sample. Patients with the A/G and $\mathrm{G} / \mathrm{G}$ genotypes (IVS2-36A $>\mathrm{G}$ ) had a significant increase for CCM risk (OR, 3.08; 95\% CI, 1.5-5.9 and OR, 4.3; 95\% CI, 1.4-22.6) and the same was observed for the polymorphism c.915 G> A (genotype G/A OR, 6.1; 95\% CI, 3.0-12.6 and genotype A/A OR, 2.79). In addition, the polymorphisms c.358 G>A in exon $4\left(\chi^{2}, 15.977 ; \mathrm{P}<0.04\right)$ and c.915 $\mathrm{G}>\mathrm{A}$ in exon $8\left(\chi^{2}\right.$, $18.109 ; \mathrm{P}<0.02)$ were significantly associated with different
\end{abstract}

Correspondence to: Dr Rosalia D'Angelo, Department of Biomorphology and Biotechnologies, Division of Biology and Genetics, University of Messina, via C. Valeria 1, I-98125 Messina, Italy E-mail: rdangelo@unime.it

Key words: cerebral cavernous malformations and risk, CCM2 polymorphisms and symptoms, genetic screening in Italian population, haplotype distribution types of symptoms. Haplotype analysis, performed only on polymorphisms c.358 G>A (p.Val120Ile), c.915 G>A (p.Thr305 Thr) and IVS2-36A $>$ G, shows that haplotype GAG (+--) significantly increased among CCM sporadic patients compared to the control group. Significant differences between patients and controls were observed only for IVS2-36A $>$ G and c.915 G>A polymorphisms indicating their possible association with sporadic CCMs and an increased risk of CCM. On the other hand, polymorphisms c.358 G>A and c.915 G>A were associated with a more benign course of the disease. These data were confirmed by the haplotype GAG (+--) frequencies.

\section{Introduction}

Cerebral cavernous malformations (CCMs; OMIM 116860) are vascular abnormalities, predominately localized in the brain, characterized by abnormally enlarged sinusoidal channels, with a simple endothelial lining devoid of elastin and smooth muscle (1). CCMs affect up to $0.5 \%$ of the human population $(2,3)$ although only $20-30 \%$ of affected individuals develop symptomatic disease (4,5). CCMs have been reported in infants, children, and old people, but the majority of patients present with symptoms between the second and fifth decades. The most common manifestations include seizures, recurrent headaches, hemorrhagic stroke and focal neurological deficits $(2,3)$. CCM can arise sporadically or may be inherited as an autosomal dominant condition with incomplete penetrance and variable clinical expression.

Three genes, CCM1 (KRIT1), CCM2 (MGC4607) and $C C M 3$ (PDCD10), encoding the proteins krev/rapl interacting trapped 1 (Krit1), malcavernin/OSM, and programmed cell death 10 (PDCD10)/CCM3 respectively, are involved in CCM development since mutations in these genes cause loss of function of gene proteins and result in CCM (6-10). CCM proteins are expressed in most tissues, including microvascular endothelium, and regulate diverse aspects of endothelial cell morphogenesis and blood vessel stability, such as cellcell junctions, cell shape and polarity, or cell adhesion to the extracellular matrix. Krit1 interacts with Rap-1A (Krev-1) (11), a member of the Ras superfamily of GTPases, with integrin cytoplasmic domain associated protein (ICAP1) $\alpha$ and 
the phosphotyrosine binding (PTB) domain of malcavernin $(10,12)$.

The malcavernin protein may function as a scaffolding protein for MAP kinases (mitogen-activated protein kinase) that are essential in $\mathrm{p} 38$ activation responding to osmotic stress including MEKK (mitogen-activated protein kinase kinase kinase 3) and MKK3 (mitogen-activated protein kinase kinase); it also binds to Rac and actin $(13,14)$.

Finally, PDCD10 forms a complex with Krit1 and malcavernin proteins. It interacts directly with malcavernin independent of Krit1-malcavernin interaction (15). Malcavernin then links Krit1 and PDCD10 which alone would have little affinity with each other $(13,16)$ and directly interacts with PDCD10 in the signalling pathways essential for vascular development and for CCM pathogenesis (13). Moreover, mutations in the PTB domain of malcavernin (amino acids 66-224), on conserved residues critical for NPXY/F motif binding, are deleterious and can lead to inactivation of the protein.

It has been demonstrated, that a noted CCM2 missense mutation, p.L198R, located in the PTB domain, was able to inhibit the malcavernin interaction with Krit1 (17). Similar results have been observed with p.F217A, an engineered mutation (18). In addition, the latest data on a mutant protein lacking, demonstrated that an intact malcavernin domain, located N-terminally of the PTB domain (amino acid residues 11-68), is essential for Krit1 binding to malcavernin (16).

While familial CCMs are characterized by the presence of multiple lesions, an evolutive condition as assessed by the strong correlation between patient age and number of lesions $(3,19,20)$, sporadic cases mostly have a single lesion (Fig. 1) and often occur in association with developmental venous anomalies. They are not inherited and do not carry a CCM gene germline mutation and do not have any known clinically affected relative. Sporadic cases with multiple lesions may be due to unrecognized familiarity (occult germ line mutations), multiple CCMs in association with a single developmental venous anomaly, or multiple CCMs after craniospinal irradiation.

Furthermore, familial cerebral cavernous malformations may show a very variable phenotype due to a highly variable penetrance of mutations. This variability seems related to the localization of mutations and may determine subtle or incomplete clinical manifestations obscuring the pattern of genetic transmission. As a result sometimes either mimicking a recessive trait in a given family or a sporadic condition in a family with an apparently negative history (21). In our recent study on mutation analysis of CCM1, CCM2 and CCM3 genes in a cohort of Italian patients with cerebral cavernous malformation, both sporadic and familial, sixteen mutations were identified, and only two in sporadic patients (22).

In addition, we found that only the sporadic patients negative for mutations in the three CCM genes and whose relatives were negative to MRI, had five variations in the CCM2 gene (data not shown), which proved to be the known polymorphisms; some detected previously by Denier et al (17) in families with CCM negative to molecular screening for $C C M 1$ mutation, and by Pileggi et al (23) in the affected members of a large Italian family harbouring a CCM1 mutation and carrying genetic variations in CCM1, CCM2 and CCM3 gene. Three of these polymorphisms are located in the coding sequence of the CCM2 gene (c.157 G>A in exon 2, c.358 $\mathrm{G}>\mathrm{A}$ in exon 4 and c.915 $\mathrm{G}>\mathrm{A}$ in exon 8).

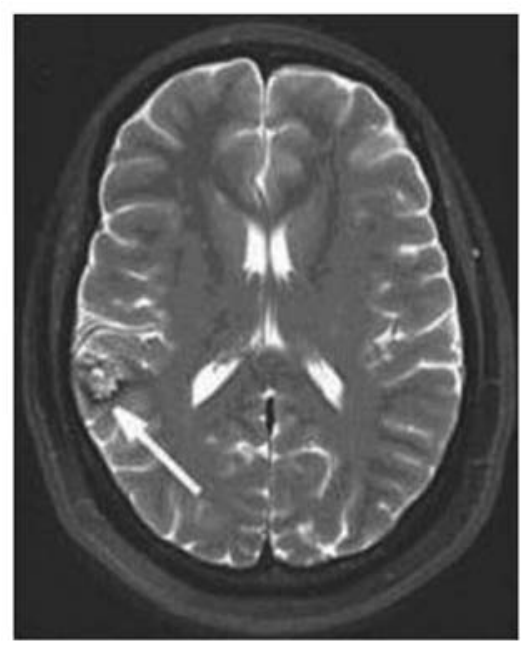

Figure 1. Radiological features of cerebral cavernous malformations (CCMs). T2 weighted MRI shows a right posterior temporoparietal cavernous malformation that exhibits the characteristic 'mulberry' appearance (arrow).

c. $157 \mathrm{G}>\mathrm{A}$ and c.358 $\mathrm{G}>\mathrm{A}$ are non-synonymous polymorphisms leading to substitutions p.Val53Ile and p.Val120Ile respectively; p.Val120Ile resides in the PTB domain of the malcavernin protein while p.Val53Ile in the domain located $\mathrm{N}$-terminally to PTB domain that, as mentioned above, is essential for krit1 binding to malcavernin.

c.915 G>A is a synonymous polymorphism leading to a silent alteration at amino acid position 305 (p.Thr305Thr) which, as is well known, while not affecting the protein structure, might be liable to alter gene function. Nothing has been reported, in literature, on the polymorphisms IVS2-36A $>\mathrm{G}$ and IVS8 $+119 \mathrm{C}>\mathrm{T}$ residing in intronic regions and so able to lead to exon skipping or to create new splice sites.

Therefore, in this study, we decided to undertake a casecontrol study to analyze the possible relationships between these polymorphisms and sporadic cerebral cavernous malformations, induced mainly by the fact that our polymorphism detection is related to a cohort of patients who were sporadic and negative to CCM genes mutation analysis, performed by direct DNA sequencing and subsequent Multiplex LigationDependent Probe Amplification (MLPA) analysis, and that little is known in literature on these polymorphisms.

\section{Materials and methods}

Patients. A total of 91 CCM patients (49 male and 42 female) were recruited. Detailed clinical and neuroimaging information on patients and their relatives were collected through direct interview by review of the medical charts, before CCM gene molecular analysis and after providing their written informed consent.

On the basis of pedigree analysis and in the absence of relatives positive to biomolecular investigation and/or MRI (standard spin echo and fast turbo spinecho T1- and T2-weighted axial, coronal, and/or sagittal images) the patients were considered sporadic. In each patient, lesions were identified based on typical charateristics and were classified according to number, localization and size. Lesions were single in 87 patients $(95.6 \%)$ and multiple in 4 patients $(4.4 \%)$. 
Table I. Demographic and disease data on CCM sporadic patients and controls.

A, CCM sporadic patients $(\mathrm{n}=91)$

\begin{tabular}{lccc}
\hline & & & \multicolumn{2}{c}{ Age at onset of symptoms $^{\mathrm{a}}$} \\
\cline { 2 - 4 } Gender & $\mathrm{n}$ & Mean \pm SD & Range \\
\hline Male & 47 & $41.7 \pm 22.5$ & $1-79$ \\
Female & 36 & $41.9 \pm 17.9$ & $14-69$ \\
Overall & 83 & $41.7 \pm 20.6$ & $1-79$ \\
Lesion number & $4 / 91>1$ Lesion & & 43 \\
Lesion seat & & & \\
$72 / 91$ Supratentorial & & & \\
$12 / 91$ Subtentorial & & \\
$7 / 91$ Spinal-cerebellar & & \\
Male + female (asymptomatic) 2+6 & & \\
Asymptomatic & 8 & \\
$>$ One symptom & 4 & \\
Symptoms & & \\
Headache & 32 & \\
Epilepsy & 22 & \\
Cerebral hemorrhage & 18 & \\
Focal neurological deficits & 7 & \\
\hline
\end{tabular}

B, Healthy controls $(n=100)$

\begin{tabular}{lrrrr}
\hline \multirow{2}{*}{ Gender } & & \multicolumn{3}{c}{ Age } \\
\cline { 4 - 5 } & $\mathrm{n}$ & Mean \pm SD & Range & Median \\
\hline Male & 54 & $43.5 \pm 17.9$ & $10-78$ & 42 \\
Female & 46 & $43.1 \pm 12.9$ & $16-60$ & 44 \\
Overall & 100 & $43.36 \pm 15.7$ & $10-78$ & 42 \\
\hline
\end{tabular}

${ }^{a}$ The age at onset of symptoms in all patients (with the exception of asymptomatic patients) coincides with the age at diagnosis. $\mathrm{P}>0.05$ indicates no significant differences. Statistical analysis was tested by the Student's t-test. CCM, cerebral cavernous malformation; SD, standard deviation.

The latter had two lesions. In 72/91 (79.1\%) patients, lesions were located supratentorially (frontal, temporal, parietal, occipital). In 12/91 (13.2\%) lesions were subtentorial (midbrain) and in $7 / 91(7.7 \%)$, were spinal-cerebellar (Table I). The data available did not reveal the existence of patients with skin, spinal cord, retinal, hepatic or vertebral lesions. Additional clinical data included: age of symptoms onset and neurological events classified in: headache, epilepsy, cerebral hemorrhages and focal neurological deficits.

Headache was reported in 32 patients, epilepsy in 22, cerebral hemorrhages in 18 and focal neurological deficits in 7; 4 patients have more than one symptom, while 8 patients were asymptomatic (Table I). With the exception of the asymptomatic patients, the age at onset of symptoms, in all patients examined, coincides with the age at diagnosis and the patient's age at the time of recruitment. The mean age at onset of symptoms was $41.7 \pm 20.6$ years (median, 43.0 years; range, 1-79 years) (Table I).
The control group consisted of 100 unrelated, randomly selected, ethnically matched, healthy individuals. Demographic data on controls are summarized in Table I. Age at onset of symptoms of male vs. female was matched in the CCM patients, as well as age of male versus female in the controls. Overall patients age at onset of symptoms versus overall healthy control age were matched. Table I indicates no significant differences $(\mathrm{P}<0.05)$. This study was approved by the Scientific Ethics Committee of the Azienda Ospedaliera UniversitariaPoliclinico 'G. Martino' Messina. Informed consent was obtained from all patients and controls.

Polymorphisms of the CCM2 gene. Among the five polymorphisms of CCM2 gene identified, two are located in non-coding regions (introns): IVS2-36A > G (rs2304689) and IVS8 +119 C > T (rs2289369); three are in the coding region: two non-synonymous, c.157 G>A in exon 2 (rs2107732) leading to the substitution of a valine by isoleucine at amino acid posi- 
Table II. Oligonucleotide primer sequences used for genotyping.

\begin{tabular}{|c|c|c|c|c|c|}
\hline Gene & Site & Polymorphism & Primers $\left(5^{\prime}-3^{\prime}\right)$ & $\mathrm{Ta}\left({ }^{\circ} \mathrm{C}\right)$ & $\begin{array}{l}\text { Expected amplicon } \\
\text { size (bp) }\end{array}$ \\
\hline CCM2 & Exon 2 & c. $157 \mathrm{G}>\mathrm{A}$ & $\begin{array}{l}\text { (F) CTA CTT CTG TTT GTT AAC CAT A } \\
\text { (R) AGA GTG TCT GGT GGA TAC AAG C }\end{array}$ & 51.7 & 329 \\
\hline CCM2 & Exon 3 & IVS2-36A>G & $\begin{array}{l}\text { (F) GAA GCA CTT GGT TTG TGC TC } \\
\text { (R) AGC CAA GTG TAC CCA TAA TGT GA }\end{array}$ & 52.4 & 299 \\
\hline CCM2 & Exon 4 & c. $358 \mathrm{G}>\mathrm{A}$ & $\begin{array}{l}\text { (F) TTT GTC ACA TGT GTG ACA TC } \\
\text { (R) ACC CAA CAC GAA GCT GCA A }\end{array}$ & 53.0 & 386 \\
\hline CCM2 & Exon 8 & $\begin{array}{l}\text { c. } 915 \mathrm{G}>\mathrm{A} \\
\text { IVS8+119 C }>\mathrm{T}\end{array}$ & $\begin{array}{l}\text { (F) GAA GCC ACC CGC TCA CAT } \\
\text { (R) AGC AAA ATT GAC CAA GAG T }\end{array}$ & 56.3 & 291 \\
\hline
\end{tabular}

Ta, amplification $\mathrm{T}$.

Table III. Association between c.358 G>A and c.915 G>A polymorphisms and symptoms in CCM patients.

\begin{tabular}{|c|c|c|c|c|c|c|c|}
\hline \multirow[b]{2}{*}{ Exon } & \multirow[b]{2}{*}{ Polymorphism } & \multirow[b]{2}{*}{ Amino acid substitution } & \multirow[b]{2}{*}{ Symptom } & \multicolumn{3}{|c|}{ Genotypes $\mathrm{n}(\%)^{\mathrm{a}}$} & \multirow[b]{2}{*}{ Total } \\
\hline & & & & GG & GA & AA & \\
\hline \multirow[t]{6}{*}{4} & c. $358 \mathrm{G}>\mathrm{A}$ & p.Val120Ile & Headache & $20(31.2)$ & $12(60.0)$ & 0 & 32 \\
\hline & & & Epilepsy & $19(29.7)$ & $3(15.0)$ & 0 & 22 \\
\hline & & & Cerebral hemorrhages & $15(23.4)$ & $3(15.0)$ & 0 & 18 \\
\hline & & & Other symptoms & $2(3.12)$ & $2(10.0)$ & $3(100)$ & 7 \\
\hline & & & Asymptomatic & $8(12.5)$ & 0 & 0 & 8 \\
\hline & & & & 64 & 20 & 3 & 87 \\
\hline \multirow[t]{6}{*}{8} & c. $915 \mathrm{G}>\mathrm{A}$ & p.Thr305Thr & Headache & $2(6.4)$ & $30(56.7)$ & 0 & 32 \\
\hline & & & Epilepsy & $10(32.2)$ & $8(15.4)$ & $4(100)$ & 22 \\
\hline & & & Cerebral hemorrhages & $8(25.8)$ & $10(19.2)$ & 0 & 18 \\
\hline & & & Other symptoms & $7(22.6)$ & 0 & 0 & 7 \\
\hline & & & Asymptomatic & $4(12.9)$ & $4(7.7)$ & 0 & 8 \\
\hline & & & & 31 & 52 & 4 & 87 \\
\hline
\end{tabular}

${ }^{a}$ The percentages given in parentheses are calculated on the total number of individuals with the same genotype. In this association those patients who had more than one symptom (4 patients) were not taken into account.

tion 53 (p.Val53Ile) and c.358 G>A in exon 4 (rs11552377) leading to the substitution of a valine by isoleucine at amino acid position 120 (p.Val120Ile); the third synonymous, c.915 G>A in exon 8 (rs2289367) leading to a silent alteration at amino acid position 305 (p.Thr305Thr).

Variation numbering is based on the cDNA sequences obtained from GenBank (accession no. NM_031443) with +1 corresponding to the A of the ATG initiation codon. SNP database www.ncb.nlm.org was also utilized.

\section{Genotyping}

Primers and polymerase chain reaction (PCR). DNA blood samples were obtained with informed consent from patients and controls. Genomic DNA was isolated from peripheral blood leukocytes by the salting out method (24) and then stored in TE buffer (10 mM Tris-HCl, 1 mM EDTA, $\mathrm{pH}$ 8.0) until analysis.

The amplification of CCM2 gene exons 2, 3, 4, 8, was performed using the pairs of primers designed according to the CCM2 published nucleotide sequence of GenBank (accession no. NG_016295). The nucleotide sequence of primers and relative expected amplicon size is shown in Table II.

PCR reaction was carried out in a $50 \mu 1$ final volume containing $0.2 \mu \mathrm{M}$ concentration of each primer, $0.8 \mu \mathrm{g}$ genomic DNA as template and 1 unit Euro Taq polymerase (EuroClone SpA Life Sciences Division, Italy). PCR was performed with a thermal cycler GeneAmp PCR System 9600 (PE Applied Biosystems, Foster City, CA) samples were subjected to 35 cycles of amplification, comprising $30 \mathrm{sec}$ of denaturation at $95^{\circ} \mathrm{C}, 1 \mathrm{~min}$ of annealing, and 
Table IV. Allele and genotype frequencies of CCM2 polymorphisms and risk.

\begin{tabular}{|c|c|c|c|c|c|c|c|c|c|}
\hline Exon & $\begin{array}{l}\text { Sequence } \\
\text { variation }\end{array}$ & $\begin{array}{l}\text { Coding } \\
\text { change }\end{array}$ & $\begin{array}{l}\text { SNP } \\
\text { reference }\end{array}$ & Genotype & $\begin{array}{l}\text { No. }(\%)^{\mathrm{a}} \\
\text { in controls }\end{array}$ & $\begin{array}{l}\text { No. }(\%)^{\mathrm{a}} \\
\text { in patients }\end{array}$ & $\begin{array}{l}\text { Odds } \\
\text { Ratio }\end{array}$ & $95 \% \mathrm{CI}$ & P-value \\
\hline 2 & c. $157 \mathrm{G}>\mathrm{A}$ & p.Val53Ile & rs2107732 & $\begin{array}{l}\text { GG } \\
\text { GA } \\
\text { AA } \\
\text { G } \\
\text { A }\end{array}$ & $\begin{array}{c}82(82) \\
18(18.0) \\
0 \\
0.91 \\
0.09\end{array}$ & $\begin{array}{c}66(72.5) \\
25(27.5) \\
0 \\
0.86 \\
0.14\end{array}$ & $\begin{array}{c}1 \\
1.7\end{array}$ & & 0.225 \\
\hline 3 & IVS2-36 A>G & Intronic & rs2304689 & $\begin{array}{l}\text { AA } \\
\text { AG } \\
\text { GG } \\
\text { A } \\
\text { G }\end{array}$ & $\begin{array}{c}74(74) \\
24(24.0) \\
2(2.0) \\
0.86 \\
0.14\end{array}$ & $\begin{array}{c}43(47.25) \\
43(47.25) \\
5(5.5) \\
0.71 \\
0.29\end{array}$ & $\begin{array}{c}1 \\
3.08 \\
4.3\end{array}$ & $\begin{array}{c}1.5-5.9 \\
1.4-22.6\end{array}$ & $<0.037$ \\
\hline 4 & c. $358 \mathrm{G}>\mathrm{A}$ & p.Val120Ile & rs 11552377 & $\begin{array}{l}\text { GG } \\
\text { GA } \\
\text { AA } \\
\text { G } \\
\text { A }\end{array}$ & $\begin{array}{c}64(64.0) \\
28(28.0) \\
8(8.0) \\
0.78 \\
0.22\end{array}$ & $\begin{array}{c}67(73.6) \\
21(23.1) \\
3(3.3) \\
0.85 \\
0.15\end{array}$ & $\begin{array}{c}1 \\
0.72 \\
0.3\end{array}$ & & 0.462 \\
\hline 8 & c. $915 \mathrm{G}>\mathrm{A}$ & p.Thr305Thr & rs2289367 & $\begin{array}{l}\text { GG } \\
\text { GA } \\
\text { AA } \\
\text { G } \\
\text { A }\end{array}$ & $\begin{array}{c}76(76.0) \\
20(20.0) \\
4(4.0) \\
0.86 \\
0.14\end{array}$ & $\begin{array}{c}33(36.3) \\
53(58.2) \\
5(5.5) \\
0.65 \\
0.35\end{array}$ & $\begin{array}{c}1 \\
6.1 \\
2.9\end{array}$ & $3.0-12.6$ & $<0.001$ \\
\hline 8 & IVS8+119 C>T & Intronic & rs2289369 & $\begin{array}{l}\mathrm{CC} \\
\mathrm{CT} \\
\mathrm{TT} \\
\mathrm{C} \\
\mathrm{T}\end{array}$ & $\begin{array}{c}48(48.0) \\
44(44.0) \\
8(8.0) \\
0.7 \\
0.3\end{array}$ & $\begin{array}{c}33(36.3 \\
45(49.4) \\
13(14.3) \\
0.61 \\
0.39\end{array}$ & $\begin{array}{c}1 \\
1.5 \\
2.4\end{array}$ & & 0.509 \\
\hline
\end{tabular}

${ }^{a}$ The percentages given in parentheses are calculated on the total number of individuals with the same genotype. In this association those patients who had more than one symptom (4 patients) were not taken into account. Odds ratio are calculated relative to subjects with the $\mathrm{G} / \mathrm{G}$ (polymorphism c.157 G>A), A/A (polymorphism IVS2-36 A>G), G/G (polymorphism c.358 G>A), G/G (polymorphism c.915 G>A) and C/C (polymorphism IVS8 +119 C>T) genotypes, respectively. OR, odds ratio; CI, confidence interval.

$30 \mathrm{sec}$ of extension at $72^{\circ} \mathrm{C}$. The final extension step was extended to $10 \mathrm{~min}$. Annealing temperature was optimized for each primer set.

Sequencing. PCR products were analyzed by direct sequencing, nucleotide sequence analysis was performed using both $5^{\prime}$ and 3 ' primers, and the dideoxynucleotide method with the BigDye Terminator Cycle Sequencing kit (vers.1.1, Applied Biosystems), on a 377 ABI PRISM Sequencer Analyzer (Applied Biosystems) (25).

Statistical analysis. Analysis of data was performed using computer software SPSS for Windows (version 6.0.1) and Epi Info (version 6.0.4).

Comparisons between the mean age at onset of symptoms of male versus female in the CCM group and overall CCM age at onset versus overall healthy control age were calculated with the Student's t-test. For each group (control and patients), allele frequencies were calculated by direct gene counting. Associations between gene genotype and risk of CCM disease were assessed by odds ratios (ORs) and 95\% confidence intervals (CIs). ORs express relative risk (OR) of CCM patients with a specific genotype and are calculated by dividing the odds of a CCM patient having a specific phenotype by the odds of a control subject having the same genotype. Estimates of statistical significance were calculated by standard $\chi^{2}$ analysis for one degree of freedom.

Descriptive analysis included Student's t-test of means and the respective standard deviation (SD) for cases and controls. A two-sided probability value of $<0.05$ was considered to indicate statistical significance. Tests for associations using multi-marker haplotypes were performed using the statistics environment ' $R$ ' package 'haplo.score' (http://www.R-project.org)

\section{Results}

There are scarce data in literature on possible associations of SNPs and CCM. We determined the frequencies and odds ratio of $C C M 2$ polymorphisms in a group of CCM sporadic patients and in a control sample. 
Table V. Haplotype frequencies c.358 G>A, c.915 G>A and IVS2-36 $\mathrm{A}>\mathrm{G}$ polymorphisms in $\mathrm{CCM}$ patients and in controls.

\begin{tabular}{lcc}
\hline Haplotype $^{\mathrm{a}}$ & Patients $(\%)$ & Controls \\
\hline G-G-A (+++) & 49.88 & 63.26 \\
G-G-G (++-) & 1.43 & 3.10 \\
G-A-A (+-+) & 6.69 & 2.24 \\
G-A-G (+--) & 27.51 & 9.39 \\
A-G-A (-++) & 14.47 & 18.63 \\
A-G-G (-+-) & 14.47 & 18.63 \\
A-A-A (--+) & 14.47 & 1.85 \\
A-A-G (---) & 14.47 & 1.50 \\
\hline
\end{tabular}

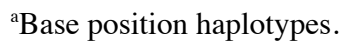

With regard to age and gender, there were no significant differences between the two groups, and no significant association was observed between the CCM patients (male and female) and age at onset of symptoms.

No significant relation between lesion sites (supratentorial, subtentorial and spinal-cerebellar) and age at onset of symptoms, nor between the type of symptom and age at onset of symptoms was found. None of the allelic variants of CCM2 gene examined appear to have any influence on the age at onset of symptoms $(\mathrm{P}>0.05)$ or on lesion site.

Polymorphisms c.358 G>A in exon $4\left(\chi^{2}, 15.977 ; \mathrm{P}<0.04\right)$ and c.915 $\mathrm{G}>\mathrm{A}$ in exon $8\left(\chi^{2}, 18.109 ; \mathrm{P}<0.02\right)$ showed, instead, a significant association with different types of symptoms (Table III). In this type of association, patients who had more than one symptom were not taken into account (4 patients).

In reference to polymorphism c.358 G>A (p.Val120Ile), approximately $60 \%$ of patients with genotype G/A suffered from headache while the remaining $40 \%$ was distributed equally among patients with epilepsy, cerebral haemorrhages and other symptoms. No patient with this genotype was asymptomatic.
Only $31.2 \%$ of patients with genotype G/G suffered from headache, while the percentages of those who suffered from epilepsy, cerebral haemorrhages and other symptoms was 29.7, 23.4 and $3.12 \%$, respectively. The proportion of asymptomatic patients with this genotype was 12.5 vs. $0 \%$ of patients with genotype G/A. All patients with genotype A/A had symptoms other than headache, epilepsy or cerebral haemorrhage.

Regarding polymorphism c.915 G>A (p.Thr305Thr), approximately $56.7 \%$ of patients with genotype G/A suffered from headache and 15.4 and $19.2 \%$ suffered from epilepsy and cerebral haemorrhages, respectively; $7.7 \%$ of patients $\mathrm{G} / \mathrm{A}$ were asymptomatic. Only $6.4 \%$ of patients with genotype $\mathrm{G} / \mathrm{G}$ suffered from headache, while the percentages of those who suffered from epilepsy, cerebral haemorrhages and other symptoms were $32.2,25.8$ and $22.5 \%$, respectively. The percentage of asymptomatic patients with genotype $\mathrm{G} / \mathrm{G}$ was $15.38 \%$. All patients with genotype A/A were affected by epilepsy.

The possible association between CCM2 polymorphisms and risk of CCM was checked and the result is shown in Table IV.

Among the polymorphisms examined, IVS2-36A $>\mathrm{G}$ and c. $915 \mathrm{G}>\mathrm{A}$, showed statistically significant differences in frequencies between patients and controls $\left[\left(\chi^{2}, 6.583\right.\right.$; $\left.\mathrm{P}<0.037) ;\left(\chi^{2}, 14.205 ; \mathrm{P}<0.001\right)\right]$. With regard to polymorphism IVS2-36A $>\mathrm{G}$, the prevalence of the wild-type CCM2 A/A genotype was significantly lower in CCM group (47.4\%) than in the control sample (74\%). We also found that the frequency of patients carrying the $\mathrm{A} / \mathrm{G}$ genotype among the patient group $(47.25 \%)$ was 2 -fold higher than among the controls $(24 \%)$.

In the same manner, the frequency of $\mathrm{G} / \mathrm{G}$ genotype was found to be higher among CCM patients (5.5\%) compared with control group (2\%). Patients with the $\mathrm{A} / \mathrm{G}$ and $\mathrm{G} / \mathrm{G}$ genotypes had a significant increase for CCM risk (OR, 3.08; 95\% CI, 1.5-5.9 and OR, 4.3; 95\% CI, 1.4-22.6). Similarly, for c. $915 \mathrm{G}>$ A polymorphism, the frequency of genotype $\mathrm{G} / \mathrm{G}$ in patients was $36.3 \%$ compared with $76 \%$ of controls. The frequency of patients carrying the G/A genotype among the patient group $(58.2 \%)$ was about 3 -fold higher than among the controls (20\%); however the frequency of genotype A/A was

Table VI. Prediction of the effects of CCM2 polymorphisms on malcavernin protein structure and splicing.

\begin{tabular}{|c|c|c|}
\hline CCM2 gene polymorphisms & $\begin{array}{l}\text { Effects on protein } \\
\text { PolyPhen prediction/SIFT prediction }\end{array}$ & $\begin{array}{l}\text { Effects on splicing } \\
\text { SpliceAid }\end{array}$ \\
\hline $\begin{array}{l}\text { c. } 157 \mathrm{G}>\mathrm{A} \\
\text { p.Val53Ile }\end{array}$ & & No effects \\
\hline $\begin{array}{l}\text { IVS2-36 A }>G \\
\text { Intronic }\end{array}$ & Benign & No effects \\
\hline $\begin{array}{l}\text { c. } 358 \mathrm{G}>\mathrm{A} \\
\text { p.Val120Ile }\end{array}$ & Benign & No effects \\
\hline $\begin{array}{l}\text { c.915 G>A } \\
\text { p.Thr305Thr }\end{array}$ & Benign & No effects \\
\hline $\begin{array}{l}\text { IVS8+119 C>T } \\
\text { Intronic }\end{array}$ & & No effects \\
\hline
\end{tabular}


only slightly higher in patients $(5.5 \%)$ compared to controls. Patients with the G/A and A/A genotypes had a significant increase for CCM risk (OR, 6.1; 95\% CI, 3.0-12.6 and OR, 2.9). No statistically significant differences were detected between patients and controls for the other three polymorphisms ( $\mathrm{P}>0.05$ in all cases).

Therefore, haplotype analysis was performed only on polymorphisms c.358 G>A (p.Val120Ile), c.915 G>A(p.Thr305 Thr) and IVS2-36A $>$ G. Naturally, the complete wild-type haplotype, G-G-A (+++) was the most frequent condition: $63.26 \%$ in the controls and $49.88 \%$ in CCM patients; the frequency of haplotype G-A-G (+--) was significantly higher in CCM patients than in the control group (27.51 vs. $9.39 \%$, respectively; hap-score $=3.07845 ; \mathrm{P}=0.001)($ Table $\mathrm{V})$. No significant difference in the remaining haplotype frequencies was observed between CCM patients and control group.

SIFT, PolyPhen and SpliceAid predictions. With the aim of understanding the possible impact of c.157 G>A p.Val53Ile, c.358 G>A p.Val120Ile and c.915 G>A p.Thr305Thr polymorphisms in the CCM2 gene protein SIFT and PolyPhen algorithms were used. Predictions analysis indicated that these polymorphisms not are damaging and are predicted to be benign and not to affect the protein function.

SpliceAid prediction analysis indicated that all five polymorphisms examined have no effects on splicing (Table VI).

\section{Discussion}

One of the characteristics of sporadic CCMs is that it is more likely to have a benign course (26) than familial CCMs that are more likely to haemorrhage, grow, and form new lesions; moreover, CCM patients with mutations in CCM2 have a lower number of gradient-echo sequence lesions than those with mutations in $C C M 1$ or $C C M 3$, and the number of lesions increases more slowly with age than in patients with $C C M 1$ mutations (27).

In the present study, a possible relationship between five known polymorphisms of CCM2 gene and sporadic CCMs was evaluated, starting from the ascertainment that in the cohort of patients, both sporadic and familial previously examined by us, only the sporadic patients showed these polymorphisms and were negative for CCM mutations (unpublished data) with the exception of two carrying two mutations in CCM2 gene (22).

Previously, in literature, some of these polymorphisms were described only in families with $\mathrm{CCM}$, resulting negative to molecular screening for CCMI mutation (17) or in the affected members of a family harbouring a CCM1 mutation and carrying genetic variations in $C C M 1, C C M 2$ and CCM3 genes (23): no correlation analysis has so far been conducted.

Our statistical data showed that the frequencies of CCM2 IVS2-36A > G (rs2304689) and c.915 G>A (rs2289367) polymorphisms were significantly different between CCM patients and control group; in particular, genotypes $\mathrm{AG}$ and GG (for IVS2-36A > G polymorphism) and GA and AA (for c.915 G>A polymorphism) were more frequent in patients than in the control group. Patients with these genotypes had a significant increase in risk for CCM than those with wildtype genotype.
In addition, we found a significant association between CCM2 c.358 G>A (rs11552377) and c.915 G>A (rs2289367) polymorphisms and the different types of symptoms related to CCM.

With regard to c.358 $\mathrm{G}>\mathrm{A}$ polymorphism, it would appear that the presence of genotype G/A predisposes to a higher occurrence of a 'potentially disabling' symptomatology (such as headache) rather than to a 'possibly life-threatening' symptomatology (such as epilepsy, cerebral haemorrhage, and other symptoms). The latter, in fact, were less frequent in patients with this genotype. Only $2.3 \%$ of our patients presented genotype A/A and symptoms other than headache, epilepsy or cerebral haemorrhage.

The same trend was observed for the c.915 G>A polymorphism: heterozygous genotype G/A, again, seems to be associated with a 'potentially disabling' symptomatology. It is possible, therefore, to assume that the finding of these two polymorphisms in patients with sporadic CCMs may be associated with a more benign course of the disease rather than in patients with wild-type genotype. This hypothesis is supported by the results of prediction studies conducted using SIFT, PolyPhen and SpliceAid algorithms, which show that the five polymorphisms are not damaging and do not affect the protein function. This is particularly significant for polymorphism c.358 G>A (rs11552377) (p.Val120Ile) that resides in the malcavernin PTB domain of protein and for which we have identified the above indicated association.

An amino acid substitution that alters the structure of the malcavernin protein PTB domain may be able to interfere with Krit1/malcavernin/PDCD10 complex formation and with subsequent signalling cascade (2). Only 4/91 of our patients had more than one lesion, and, neuroimaging data were insufficient to assess the existence of a correlation between these polymorphisms and the number or size of lesions. Based on the sample of our population examined, it appears that among the five polymorphisms analyzed, only IVS2-36A $>\mathrm{G}$ and c.915 G>A were significantly associated with sporadic CCMs and an increased risk of CCM. In addition, polymorphisms c.915 G>A and c.358 G>A were associated with a more benign course of the disease. In agreement with this, haplotype analysis shows that haplotype GAG (+--) was significantly increased among sporadic CCM patients compared to the control group.

It would be of interest to perform the same analysis in patients with sporadic CCM belonging to non-Italian populations in order to determine whether this haplotype has the same trend. If this is confirmed, the examination of this haplotype in CCM patients may represent a potential biomarker, and a useful tool for doctors. We believe it is very important to use molecular screening and genetic counseling to identify, as early as possible, unaffected mutation carriers and sporadic subjects with apparent negative family history.

\section{Acknowledgements}

This study was approved by the Scientific Ethics Committee of the Azienda Ospedaliera Universitaria-Policlinico 'G. Martino' Messina. The authors thank all patients and healthy controls who participated in this study. 


\section{References}

1. Clatterbuck RE, Eberhart CG, Crain BJ and Rigamonti D Ultrastructural and immunocytochemical evidence that an incompetent blood-brain barrier is related to the pathophysiology of cavernous malformations. J Neurol Neurosurg Psychiatry 71: 188-192, 2001.

2. Labauge P, Denier C, Bergametti F and Tournier-Lasserve E: Genetics of cavernous angiomas. Lancet Neurol 6: 237-244, 2007.

3. Revencu N and Vikkula M: Cerebral cavernous malformation: new molecular and clinical insights. J Med Genet 43: 716-721, 2006.

4. Otten P, Pizzolato GP, Rilliet B and Berney J: 131 cases of cavernous angioma (cavernomas) of the CNS, discovered by retrospective analysis of 24,535 autopsies. Neurochirurgie 35: 82-83, 128-131, 1989 (In French).

5. Robinson JR, Awad IA and Little JR: Natural history of the cavernous angioma. J Neurosurg 75: 709-714, 1991.

6. Craig HD, Günel M, Cepeda O, Johnson EW,Ptacek L, Steinberg GK, Ogilvy CS, Berg MJ, Crawford SC, Scott RM, Steichen-Gersdorf E Sabroe R, Kennedy CT, Mettler G, Beis MJ, Fryer A, Awad IA and Lifton RP: Multilocus linkage identifies two new loci for a mendelian form of stroke, cerebral cavernous malformation, at 7p15-13 and 3q25.2-27. Hum Mol Genet 7: 1851-1858, 1998.

7. Bergametti F, Denier C, Labauge P, Arnoult M, Boetto S, Clanet M, Coubes P, Echenne B, Ibrahim R, Irthum B, Jacquet G, Lonjon M, Moreau JJ, Neau JP, Parker F, Tremoulet M, TournierLasserve E and Société Française de Neurochirurgie: Mutations within the programmed cell death 10 gene cause cerebral cavernous malformations. Am J Hum Genet 76: 42-51, 2005.

8. Verlaan DJ, Laurent SB, Rochefort DL, Liquori CL, Marchuk DA, Siegel AM and Rouleau GA: CCM2 mutations account for $13 \%$ of cases in a large collection of kindreds with hereditary cavernous malformations. Ann Neurol 55: 757-758, 2004

9. Whitehead KJ, Plummer NW, Adams JA, Marchuk DA and Li DY: Ccm1 is required for arterial morphogenesis: implications for the etiology of human cavernous malformations. Development 131: 1437-1448, 2004.

10. Zawistowski JS, Serebriiskii IG, Lee MF, Golemis EA and Marchuk DA: KRIT1 association with the integrin-binding protein ICAP-1: a new direction in the elucidation of cerebral cavernous malformations (CCM1) pathogenesis. Hum Mol Genet 11: 389-396, 2002.

11. Serebriiskii I, Estojak J, Sonoda G, Testa JR and Golemis EA: Association of Krev-1/rapla with Krit1, a novel ankyrin repeatcontaining protein encoded by a gene mapping to 7q21-22. Oncogene 15: 1043-1049, 1997.

12. Zhang J, Rigamonti D, Dietz HC and Clatterbuck RE: Interaction between krit1 and malcavernin: implications for the pathogenesis of cerebral cavernous malformations. Neurosurgery 60: 353-359, 2007.

13. Voss K, Stahl S, Schleider E, Ullrich S, Nickel J, Mueller TD and Felbor U: CCM3 interacts with CCM2 indicating common pathogenesis for cerebral cavernous malformations. Neurogenetics 8 : 249-256, 2007

14. Uhlik MT, Abell AN, Johnson NL, Sun W, Cuevas BD, Lobel-Rice KE, Horne EA, Dell'Acqua ML and Johnson GL: Rac-MEKK3-MKK3 scaffolding for p38 MAPK activation during hyperosmotic shock. Nat Cell Biol 5: 1104-1110, 2003.

15. Li X, Zhang R, Zhang H, He Y, Ji W, Min W, Zhang H, He Y, Ji W, Min W and Boggon TJ: Crystal structure of CCM3, a cerebra cavernous malformation protein critical for vascular integrity. J Biol Chem 285: 24099-24107, 2010.
16. Stahl S, Gaetzner S, Voss K, Brackertz B, Schleider E, Sürücü O, Kunze E, Netzer C, Korenke C, Finckh U, Habek M, Poljakovic Z, Elbracht M, Rudnik-Schöneborn S, Bertalanffy H, Sure U and Felbor U: Novel CCM1, CCM2, and CCM3 mutations in patients with cerebral cavernous malformations: in-frame deletion in CCM2 prevents formation of a CCM1/CCM2/CCM3 protein complex. Hum Mutat 29: 709-717, 2008.

17. Denier C, Goutagny S, Labauge P, Krivosic V, Arnoult M, Cousin A, Benabid AL, Comoy J, Frerebeau P, Gilbert B, Houtteville JP, Jan M, Lapierre F, Loiseau H, Menei P, Mercier P, Moreau JJ, Nivelon-Chevallier A, Parker F, Redondo AM, Scarabin JM, Tremoulet M, Zerah M, Maciazek J, Tournier-Lasserve E and Société Française de Neurochirurgie: Mutations within the MGC4607 gene cause cerebral cavernous malformations. Am J Hum Genet 74: 326-337, 2004.

18. Zawistowski JS, Stalheim L, Uhlik MT, Abell AN, Ancrile BB, Johnson GL and Marchuk DA: CCM1 and CCM2 protein interactions in cell signaling: implications for cerebral cavernous malformations pathogenesis. Hum Mol Genet 14: 2521-2531, 2005.

19. Labauge P, Laberge S, Brunereau L, Levy C and TournierLasserve E: Hereditary cerebral cavernous angiomas: clinical and genetic features in 57 French families. Lancet 352: 1892-1897, 1998.

20. Rigamonti D, Drayer BP, Johnson PC, Hadley MN, Zabramski J and Spetzler RF: Cerebral cavernous malformations. Incidence and familial occurence. N Engl J Med 319: 343-347, 1988.

21. Gianfrancesco F, Cannella M, Martino T, Maglione V, Esposito T, Innocenzi G, Vitale E, Liquori CL, Marchuk DA and Squitieri F: Highly variable penetrance in subjects affected with cavernous cerebral angiomas (CCM) carrying novel CCM1 and CCM2 mutations. Am J Med Genet B Neuropsychiatr Genet 144B: 691-695, 2007.

22. D'Angelo R, Marini V, Rinaldi C, Origone P, Dorcaratto A, Avolio M, Goitre L, Forni M, Capra V, Alafaci C, Mareni C, Garrè C, Bramanti P, Sidoti A, Retta SF and Amato A: Mutation analysis of $C C M 1, C C M 2$ and $C C M 3$ genes in a cohort of Italian patients with cerebral cavernous malformation. Brain Pathol 21: 215-224, 2011

23. Pileggi S, Buscone S, Ricci C, Patrosso MC, Marocchi A, Brunori P, Battistini S and Penco S: Genetic variations within KRIT1/CCM1, MGC4607/CCM2 and PDCD10/CCM3 in a large Italian family harbouring a Krit1/CCM1 mutation. J Mol Neurosci 42: 235-242, 2010.

24. Sambrook J, Fritsch EF and Maniatis TF (eds): Molecular Cloning: A Laboratory Manual. Cold Spring Harbor, Cold Spring Harbor Press, New York, 1989.

25. Sidoti A, D'Angelo R, Rinaldi C, De Luca G, Pino F, Salpietro C, Giunta D, Saltalamacchia F and Amato A: Distribution of the mutated delta 32 allele of the CCR5 gene in a Sicilian population. Int J Immunogenet 32: 193-198, 2005.

26. Maiuri F, Cappabianca P, Gangemi M, De Caro Mdel B, Esposito F, Pettinato G, de Divitiis O, Mignogna C, Strazzullo V and de Divitiis E: Clinical progression and familial occurrence of cerebral cavernous angiomas: the role of angiogenic and growth factors. Neurosurg Focus 21: e3, 2006.

27. Denier C,Labauge P,BergamettiF, MarchelliF, RiantF,Arnoult M, Maciazek J, Vicaut E, Brunereau L, Tournier-Lasserve E, Société Française de Neurochirurgie: Genotype-phenotype correlations in cerebral cavernous malformations patients. Ann Neurol 60: $550-556,2006$. 